suggesting a mechanism for the crosstalk between BMP and GCN2.

Conclusion We have discovered in Drosophila that GCN2 activation modulates BMP signalling. This effect is mediated, at least in part, by the downstream transcription factor ATF4, which inhibits the phosphorylation of MAD (insect SMAD1). Our findings indicate that this pathway is conserved between insects and mammals and this model may shed light on the pathogenesis of $\mathrm{PAH}$ and PVOD.

\section{S87 DEFICIENCY OF TOLL-LIKE RECEPTOR 3 (TLR3) EXACERBATES PULMONARY HYPERTENSION IN MICE}

${ }^{1}$ AAR Thompson, ${ }^{1} \mathrm{ND}$ Arnold, ${ }^{1} \mathrm{AT}$ Braithwaite, ${ }^{1} \mathrm{HL}$ Casbolt, ${ }^{1} \mathrm{~J}$ Iremonger, ${ }^{1} \mathrm{JA}$ Pickworth, ${ }^{2} \mathrm{C}$ Monaco, ${ }^{2} \mathrm{JE}$ Cole, ${ }^{1}$ I Sabroe, ${ }^{1} \mathrm{~A}$ Lawrie. 'University of Sheffield, Sheffield, UK; ${ }^{2}$ University of Oxford, Oxford, UK

\subsection{6/thoraxjnl-2016-209333.93}

Introduction The mechanisms regulating aberrant vascular remodelling in pulmonary arterial hypertension $(\mathrm{PAH})$ are poorly understood and treatments targeted at halting or reversing this process are lacking. Toll-like receptor 3 (TLR3) is a viral sensor and more recently has been established as a sensor of endogenous damage signals, responding to mRNA released by damaged cells. TLR3 signalling induces pro- and anti-inflammatory cytokine production and regulates inflammation-associated apoptosis and tyrosine kinase signalling. In a model of systemic arterial injury, TLR3 signalling was shown to modulate neointimal remodelling in a protective manner. TLR3 is also expressed in pulmonary artery smooth muscle (PASMCs) and endothelial cells (PAECs). We therefore hypothesised that TLR3 would play roles in pulmonary vascular remodelling.

Methods TLR3-deficient (TLR3-/-) or wild-type C57BL/6 (WT) mice were exposed to hypoxia (10\% Oxygen) and given Sugen 5416 (weekly $20 \mathrm{mg} / \mathrm{kg}$ subcutaneous injections) or maintained in normoxic conditions for 3 weeks. Haemodynamic (cardiac catheterisation and echocardiography) and histological assessments were performed after 3 weeks. Human PASMCs were serum-starved before stimulation with PDGF or poly(I:C) and proliferation was assessed after 72 hours.
Results TLR3 - / - mice developed a markedly exaggerated phenotype of PAH in response to Sugen/Hypoxia with increased right ventricular systolic pressures (WT $51.6 \mathrm{mmHg} \pm 4.6$ vs. TLR3-/- $73.0 \mathrm{mmHg} \pm 6.8 ; \mathrm{p}<0.05$, mean \pm SEM, $\mathrm{n}=6$ ), increased muscularisation of small pulmonary arteries and reduced right ventricular cardiac output (WT 424.2 RVUmin$1 \pm 84.2$ vs. TLR $3-/-283.3$ RVUmin- $1 \pm 18.4$, mean \pm SEM, $\min \mathrm{n}=6$ ) after 3 weeks. Poly(I:C) suppressed PDGF-induced PASMC proliferation in a dose-dependent manner.

Conclusions We have shown that mice deficient in TLR3 develop a markedly exaggerated haemodynamic pulmonary hypertension phenotype and human PASMC proliferation is suppressed by the TLR3 ligand, poly(I:C). Together these data imply that TLR3 signalling in disease mediates a protective phenotype in keeping with that observed in systemic vascular remodelling, and identify a protective pathway potentially amenable to therapeutic targeting.

\section{Tuberculosis: From Screening to Side Effects}

\begin{tabular}{l|l}
\hline S88 NEITHER UK TUBERCULOSIS INFECTION TESTING \\
GUIDELINE APPEARS COST-EFFECTIVE IN A \\
CONTEMPORARY HIV INFECTED POPULATION
\end{tabular}

${ }^{1} S$ Capocci, ${ }^{2} \mathrm{~J}$ Sewell, ${ }^{2} \mathrm{C}$ Smith, II Cropley, 'S Bhagani, ${ }^{1} \mathrm{~A}$ Solamalai, ${ }^{2} S$ Morris, ${ }^{2}$ A Abubakar, ${ }^{1} \mathrm{MA}$ Johnson, ${ }^{1} \mathrm{MCl}$ Lipman. ${ }^{1}$ Royal Free London NHS Foundation Trust, London, UK; ${ }^{2}$ University College London, London, UK

\subsection{6/thoraxjnl-2016-209333.94}

UK guidelines advise testing for latent tuberculosis infection (LTBI) in people with known HIV. Both National Institute for Health and Care Excellence (NICE) 2011 and 2016, and British HIV Association (BHIVA) guidelines use targeted testing, in comparison to those from other countries, notably the United States. None of these have been compared for cost-effectiveness in a contemporary HIV population.

\begin{tabular}{|c|c|c|c|c|c|c|}
\hline Strategy & $\begin{array}{l}\text { Total cost of strategy per } 10,000 \\
\text { people living with HIV }\end{array}$ & $\begin{array}{l}\text { Cases TB } \\
\text { prevented } \\
\text { (discounted) }\end{array}$ & $\begin{array}{l}\text { QALYs gained compared to no } \\
\text { testing (discounted) }\end{array}$ & $\begin{array}{l}\text { Cost/case } \\
\text { averted }\end{array}$ & $\begin{array}{l}\text { Cost/QALY compared } \\
\text { to no testing }\end{array}$ & $\begin{array}{l}\text { Incremental cost/QALY } \\
\text { compared to last strategy }\end{array}$ \\
\hline BHIVA 2011 & $f 749,274$ & 2.28 & 1.28 & $f 21,371$ & $£ 37,952$ & EXTENDED DOMINANCE \\
\hline TST in BA & $f 749,660$ & 3.9 & 2.09 & $£ 12,566$ & $£ 23,429$ & $\mathrm{f} 23,429$ \\
\hline TST in BA and MI & $f 761,797$ & 4.49 & 2.43 & $f 13,614$ & $f 25,218$ & EXTENDED DOMINANCE \\
\hline NICE 2011 & $f 788,037$ & 1.11 & 0.63 & $f 78,429$ & $f 139,281$ & DOMINATED \\
\hline IGRA in BA & $f 812,048$ & 6.83 & 3.85 & $f 16,314$ & $\mathrm{f} 28,971$ & EXTENDED DOMINANCE \\
\hline IGRA in BA and MI & f865,959 & 9.06 & 5.1 & $f 18,250$ & $£ 32,410$ & EXTENDED DOMINANCE \\
\hline IGRA in all & $\mathrm{f} 1,056,702$ & 10.17 & 5.72 & $f 35,030$ & $f 62,209$ & EXTENDED DOMINANCE \\
\hline NICE 2016 & $f 1,058,522$ & 10.17 & 5.72 & $\mathrm{f} 35,234$ & $\mathrm{f} 62,571$ & DOMINATED \\
\hline TST\&IGRA in all & $\mathrm{f1}, 219,154$ & 10.99 & 5.88 & $\mathrm{f} 47,166$ & f88,139 & EXTENDED DOMINANCE \\
\hline $\begin{array}{l}\text { TST\&IGRA\&CXR\&IS } \\
\text { in all }\end{array}$ & $f 1,999,789$ & 20.58 & 10.44 & $\mathrm{f} 63,142$ & f124,393 & EXTENDED DOMINANCE \\
\hline
\end{tabular}

BA - Black African, BHIVA - British HIV Association, CXR - chest X ray, IGRA - Interferon-gamma release assay, IS - induced sputum, MI - middle [TB] incidence countries, NICE - National Institute of Health and Care Excellence, QALY - Quality adjusted life year, TB - tuberculosis (includes active disease and subclinical tuberculosis cases), TST - tuberculin skin test. 